\title{
A Theory of the Mechanism of Cerebral Vasospasm and Its Reversal, the Role of Calcium and Cyclic AMP
}

\author{
ERIC W. PETERSON AND RICHARD LEBLANC
}

SUMMARY: It is proposed that the basic mechanism of vasospasm which somerimes follow's subarachnoid hemorrhage is dependent on increased free intracellalar calcium ion produced by spasmogens from closely applied extravasated blood. Relaxation of this spasm occurs when the intracellular cyclic AMP levels are raised, resulting in sequestration of calcium ion by the vascular smooth mascle cell sarcoplasmic reticulam.

RÉSUMÉ: Il est proposé que le mécanisme de base du vasospasme, qui quelquefois fait suite à l'hémorragie méningée, est dépendant de l'augmentation de l'ion calcium intracellulaire produit par spasmogènes provenant de sang extravasé appliqué à proximité. Le relâchement de ce spasme se produit quand les niveaux d'AMP-cyclique intracellulaire sont élevés, résultant en une séquestration de l'ion calcium par le reticulum sarcoplasmique des cellules musculaires lisses vasculaires.

From the Division of Neurosurgery, University of Ottawa, Medical School.

Reprint requests 10: Dr. E. W. Peterson, 703-1081 Carling Avenue, Ottawa, Ontario KIY 4G2 Canada.
In the last three decades, the reactivity of cerebral blood vessels to subarachnoid hemorrhage has been widely recognized (Ecker and Riemenschneider, 1951). This vasospasm is commonly seen following rupture of an intracranial aneurysm of the Circle of Willis. Since this complication usually occurs after an interval of five to seven days, operative treatment is preferably delayed for a week or more, thereby increasing the danger of re-bleeding from an unclipped aneurysm. In a recent review of 321 consecutive cases, $18 \%$ of patients died of re-bleeding before operation could be performed (Drake, 1976). Once spasm is established, ischemic necrosis of the brain may occur and, combined with the problems attendant upon a bleeding aneurysm, may prove fatal. Further progress in the management of ruptured intracranial aneurysms therefore, awaits an effective approach for the prevention or reversal of vasospasm. We proposed (Peterson et al, 1973a, 1973b, 1973c, 1973d, 1975a) that the manipulation of the vascular smooth muscle adenylate cyclase-cyclic AMP system, either by phosphodiesterase inhibition with topically applied theophylline or by the exogenous supply of cyclic AMP as its dibutyryl derivative might modify cerebral vaso-constriction that sometimes follows subarachnoid hemorrhage.

A number of physiological factors affect the internal diameter of cerebral blood vessels (Kapp, 1968). Catecholamine fluorescence (Peerless and Ysaragil, 1971) and $\alpha$ and $\beta$ receptors have been described (Lowe and Gilboe, 1971; Edvinson and Owman, 1974), but the role of the sympathetic nervous system in this condition remains controversial
(Langfitt, 1974). The probable source of spasm initiating factors is the adherent blood clot enmeshed in the subarachnoid trabeculae, and the platelets in this clot (Kapp, 1968) are thought to produce the two putative spasmogens, serotonin (Echlin, 1968) and prostaglandin $\mathrm{F}_{2} \alpha\left(\mathrm{PGF}_{2} \alpha\right)$ (White et al, 1975).

Prostaglandins are a heterogeneous group of ubiquitous naturally occurring long chain fatty acids capable of exerting a wide variety of actions in different tissues and in different species. Prostaglandin $E_{1}$ has been shown to increase the levels of cyclic AMP (Borgeat et al, 1975) in many preparations by its action on adenylate cyclase, the enzyme that produces cyclic 3'5' AMP (cyclic AMP) from ATP. The consensus of most investigators is that this substance has a vasodilating effect (Pelofsky et al, 1972). Prostaglandin $F_{2} \alpha$ has only a very slight effect on the level of cyclic AMP (Borgeat et al, 1975; Barrett-Bee and Green, 1975) in many systems, but this is probably irrelevant to its action on cerebral blood vessels. It is well established as a spasmogen in experimental vasospasm (White et al, 1975) and requires the presence of extracellular calcium ion to exert its effect (Allen et al, 1976). Possibly the mechanism of action of PGF: $\alpha$ is increased cellular permeability to calcium ion (Goodman and Gilman, 1970). Thrombin stimulates the formation of it from platelets and it is also produced by brain tissue. In addition, serotonin increases PGF: $\alpha$ synthesis (White et al, 1975). Prostaglandin $F_{2} \alpha$ can be produced at the involved site by many mechanisms and experimental evidence demonstrates potent vasoconstrictor properties in many animal 
models indicating a possible role in the genesis of cerebral vasospasm (White et al, 1975). However, determinations of the presence of prostaglandin $F_{2} \alpha$ in the CSF in cerebrovascular disease (LaTorre et al, 1974; Wolfe and Namer, 1975) are inconclusive. These samples of CSF were obtained from the lumbar subarachnoid space and therefore they cannot properly reflect the concentration of the spasmogen in the closely applied and degenerating clot at the base of the brain.

Serotonin is widely distributed. In man, $90 \%$ occurs in the GI tract, $8-10 \%$ in platelets and only $1-2 \%$ exists in the central nervous system (Cooper et al., 1974). Although Kapp thought that the platelet spasmogen was not serotonin, it has been implicated by others (Pool, 1958) and has recently been extensively investigated (Allen et al., 1974). Serotonin induced vasospasm is also dependent on extracellular calcium ion (Allen et al, 1976).

We can affirm that cerebral vasospasm occurs frequently after subarachnoid hemorrhage, that it is a serious condition, and that the problems occasioned by it are associated with a high mortality. Spasm is seen in association with blood in the subarachnoid space, where the thin walled and naked cerebral blood vessels lack a well developed adventitia and have no vasa vasorum (Fisher). Because the walls lack perfusion by their own capillaries to clear effective concentrations of stimulating substances, cerebral vascular smooth muscle cells are probably vulnerable to vasoactive agents originating in the adherent blood clot in the subarachnoid space. The substances frequently implicated are prostaglandin $F_{2} \alpha$ and serotonin, both produced by platelets, both requiring extracellular calcium, and both increasing cellular calcium permeability (White et al, 1975).

We have postulated that increasing the cyclic AMP content of the spastic smooth muscle cell would also result in the reversal of established spasm, and we reported these observations using theophylline and dibutyryl cyclic AMP (Peterson et al, 1973a, 1973b, 1973c, 1973d). Re-

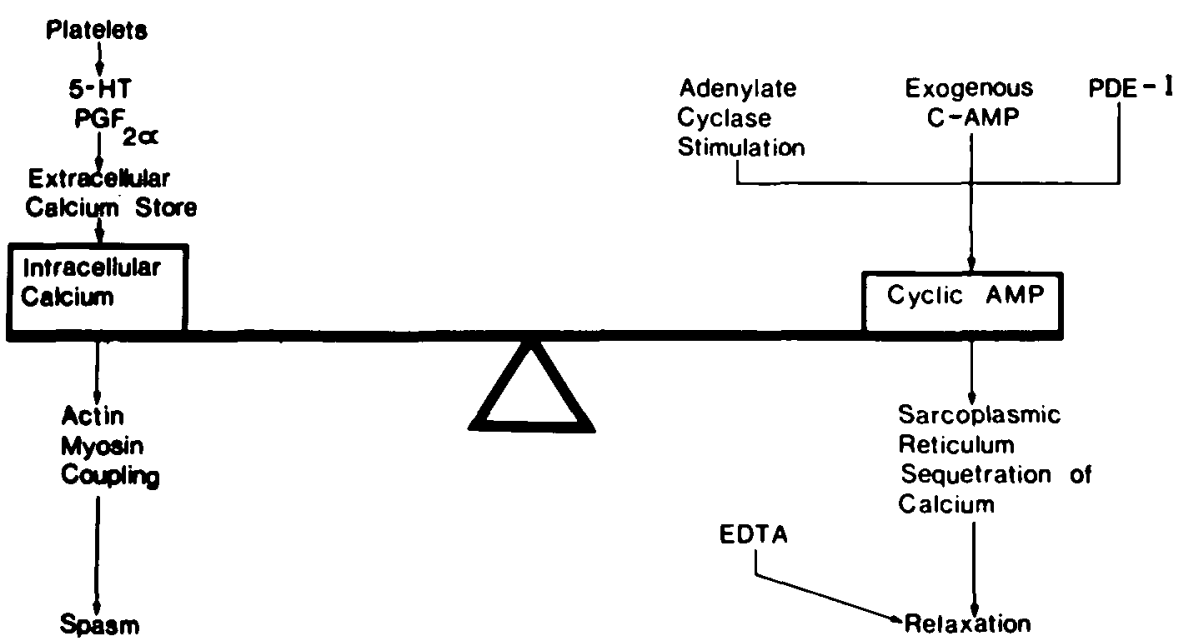

Figure 1-Platelets in the extravasated blood clot produce Serotonin (5-HT) and Prostaglandin $F_{2} \alpha$ (PGF2 $\alpha$ ) which alter the smooth muscle cell membrane permeability to extracellular calcium. This results in an increase in extracellular calcium which is then available for actin and myosin coupling resulting in vasospasm.

Increasing the levels of cyclic AMP inside the cell by stimulation of adenylate cyclase, by exogenous supply of cyclic AMP in its dibutyryl form or by phosphodiesterase inhibition, results in sequestration of the calcium by the sarcoplasm reticulum and subsequent decoupling of actin and myosin with ultimate vaso relaxation.

cently, this has been confirmed by others (Flamm, 1975). Papaverine, a widely used vasodilator, is a potent phosphodiesterase inhibitor (Triner et al, 1970) and may exert its action by increasing the cyclic AMP of the vascular smooth muscle cell. We have recently established that increasing the intracellular cyclic AMP levels by topical application of dibutyryl cyclic AMP can reverse prostaglandin $F_{2} \alpha$ induced spasm (Peterson et al, 1975b) of the basilar artery of the cat. Cyclic AMP is also a ubiquitous substance with many effects, and has been characterized as the "second messenger" in the action of many hormones (Robison et al, 1971a). It is synthetized from adenylate cyclase (thought to be the $B$ receptor [Robinson et al, 1971b]), from ATP, and is degraded by phosphodiesterase to 5'AMP. There are three ways of increasing cellular cyclic AMP content; by stimulation, by phosphodiesterase inhibition and by exogenous supply of cyclic AMP in its dibutyryl form. Norepinephrine and dopamine act in the central nervous system by the alteration of the post-synaptic cyclic AMP levels (Cooper, 1975).

One of the actions of cyclic AMP is to decrease the availability of intracellular free calcium ion. Andersson (1972) believes that cyclic AMP may produce its relaxing effect by stimulating the calcium binding processes in the smooth muscle cell and in reducing the free myoplasmic calcium ion. Vascular smooth muscle contraction depends on the coupling of the contractile proteins, actin and myosin (Somlyo and Somlyo, 1970; Bohr, 1973). Myosin, the thick filament, has laterally projecting cross bridges extending towards the nearby thin actin filaments, which appear to be attached to dense bodies related to the cell membrane. Contraction would take place in a manner analagous to the sliding filament theory of skeletal muscle, where interaction between myosin and actin filaments using chemical energy derived from ATP hydrolysis results in mechanical work. This reaction is calcium dependent, but other less well understood factors, such as magnesium ion concentration, sodium ion concentration and fiber length are involved. Thus the contraction seen following mechanical irritation of cerebral blood vessels during operation, might be the result of alteration of fiber length, 
which is a determinant of the force exerted by the contractile proteins (Bohr, 1973). Calcium ions may be stored in the intracellular or extracellular calcium and the maininduced contraction requires calcium ions from both sources, the first response being dependent on intracellular calcium and the maintained slower response on extracellular calcium (Bohr, 1973). This might be relevant to the contraction produced by mechanical stimulation (Arutinov et al, 1974).

The sarcoplasmic reticulum acts as an intracellular store of calcium which it supplies or removes from the vicinity of the contractile proteins. Contraction or relaxation of vascular smooth muscle is dependent on the availability of the appropriate concentrations of this ion. The available calcium ion is influenced by the influx from extracellular supplies or by the extrusion of the intracellular ion, or by its sequestration or release by the sarcoplasmic reticulum. Relaxation of the myocardium involves activation of adenylate cyclase resulting in an increase in cyclic AMP which has the ability to stimulate calcium ion sequestration by sarcoplasmic reticulum. This is accomplished by the activation of a cyclic AMP dependent protein kinase that catalyses the phosphorylation of various proteins and results in stimulation of calcium ion transport into the sarcoplasmic reticulum (Katz, 1975). Serotonin or prostaglandin $F: \alpha$ induced spasm is dependent on extracellular calcium ion (Allen et al, 1975). By contrast, EDTA has a vasodilating action in blood induced spasm of the basilar artery of the cat by chelating calcium (Peterson, 1968).

Cerebral vasospasm can be considered to be a calcium ion dependent activation of actin and myosin coupling. Relaxation of vascular smooth muscle can be considered to be dependent on increased levels of intracellular cyclic AMP.

Serotonin is known to increase the activity of adenylate cyclase in some preparations and to decrease it in others (Goodman and Gilman, 1970; Blum, 1970), but, a membrane activ- ity of serotonin resulting in calcium entry into the cell is generally considered to be responsible for smooth muscle contraction. This effect is thought to be due to increased membrane permeability allowing calcium ion to run passively down its electrochemical gradient (Goodman and Gilman, 1970) because in resting muscle, the intracellular calcium ion concentration is $10^{-7} \mathrm{M}$, while the extracellular pool concentration is $10^{-3} \mathrm{M}$ (Bohr, 1973). It has been thought that the effects of prostaglandins were a general modulation of adenylate cyclase activity (Goodman and Gilman, 1970) and this thinking was the basis of our explanation of the spasmogenic effect of prostaglandin $F_{2} \alpha$ (Peterson et al, 1975b). Although it is true that some prostaglandins have a very marked effect on adenylate cyclase (prostaglandin $E_{1}$ in particular markedly increases the activity of this enzyme), this modulation does not seem to be the mechanism of action of prostaglandin $F_{2} \alpha$ (Borgeat et al, 1975; Barrett-Bee and Green, 1975; Goodman and Gilman, 1970). Rather, it has been suggested that prostaglandin $F_{2} \alpha$ increases cellular permeability to calcium ion and this is the basis for its spasmogenic activity. It has been postulated that these agents and possibly other spasmogens could exert their effect by increasing calcium ion influx into the vascular smooth muscle cell from extracellular sources and thus render calcium available for action and myosin coupling. Spasm could be maintained by the clot adjacent to the involved artery releasing a continuous supply of an effective concentration of the spasmogen. This could also explain the usual delay in the appearance of spasm for 5-7 days while effective concentrations were accumulating in the degenerating clot. The possible removal of these substances could be hindered by the hemorrhage blocking the CSF pathways at the base of the brain. If there is an increased level of cyclic AMP in the cell by topical application of dibutyryl cyclic AMP or by $\beta$ stimulation or by phosphodiesterose inhibition, there would be a decreased calcium ion concentration permitting ATP to be used to energize the actin-myosin decoupling with resultant vasodilatation.

Parenteral administration of $\beta$ agonists or phosphodiesterase inhibitors could not be expected to reverse established spasm, because the lack of vasa vasorum precludes the attainment of effective concentrations of cyclic AMP within the cell. However, prophylactic treatment of patients with bleeding aneurysms with $\beta$ stimulation and/or phosphodiesterase inhibition may in time accumulate enough of these agents to increase cyclic AMP levels in those cells exposed to extravasated blood. This might result in a less severe or less prolonged spasm. The effects of such a therapeutic regimen would also be felt systemically, but the topical application of drugs at the time of operation would be more restricted. We have observed that the intracisternal injections of dibutyryl cyclic AMP in cats and in monkeys, while effectively reversing blood induced vasospasm, also have resulted in epileptic seizures which seem to originate in the hippocampus. These were controlled by diazepam (Peterson et al, 1975b). This route of administration is not satisfactory for clinical treatment at present.

In summary, we propose that vasospasm may be considered a reaction by vascular smooth muscle, whereby under the influence of certain substances, an increase in the calcium ion concentration occurs inside the cell, resulting in actin and myosin coupling. It can be prolonged if there is a continued supply of spasmogen from extravasated and degenerating blood. Relaxation occurs when there is a decrease in the intracellular calcium ion concentration due to the cyclic AMP mediated sequestration of this ion by the sarcoplasmic reticulum.

\section{REFERENCES}

ALLEN, J. S., HENDERSON, L. M.. CHOU, S. N. (1974). Cerebral arterial spasm. Journal of Neurosurgery: 40 . 433-458. 
ALLEN, J. S., GROSS, C. J., HENDERSON, L. M. and CHOU, S. N. (1976). Cerebral arterial spasm, Part 4. Journal of Neurosurgery: $44,585-593$.

ANDERSSON, R. G. G. (1972). Cyclic AMP and calcium ions in mechanical and metabolic responses of smooth muscles; influence of some hormones and drugs. Acta. Physiol. Scand. Supp. 382.

ARUTINOV, A. L., BARRON, M. A., MAGOROVA, M. A. (1974). The role of mechanical factors in the pathogenesis of short term and prolonged spasm in the cerebral arteries. Journal of Neurosurgery: 40, $451-458$.

BARRETT-BEE, K. J., GREEN, L. R. (1975). The relationship between prostaglandin release and cyclic AMP levels during anaphylaxis (Anaphylaxis) in the guinea pig. Prostaglandin: 10, 589-592.

BLUM, J. J. Editor (1970). Biogenic amines as physiological regulators. A symposium held under the auspices of the Society of General Physiologists at the Marine Biological Laboratory. Woods-hole, Mass. Aug. 29 - Sept. 1, 1969. Prentice Hall and Comp. New Jersey.

BOHR, D. F. (1973). Vascular smooth muscle updated. Circ. Res. 32, 665-672.

BORGEAT, P., Labrie, F., GARNEAU, P. (1975). Characteristics of action of prostaglandins on cyclic AMP accumulation in rat anterior pituitary gland. Can. J. Biochem: $53,455-460$.

COOPER, J. R., BLOOM, F. E., ROTT, R. H. (1974). The biochemical basis of Neuropharmacology, New York, Oxford University Press, Second Edition.

DRAKE, C. G. (1976). Stroke: 7, 238.

ECHLIN, F. A. (1951). Current concepts in the etiology and treatment of vasospasm. Clin. Neurosurg: 15, 133-160.

ECKER, A., RIEMENSCHEIDER, P. A. (1951). Arteriographic demonstration of spasm of the intracranial arteries with special reference to saccular arterial aneurysms. Journal of Neurosurgery: 8, 660-667.

EDVINSON, L., OWMAN, C. (1974). Pharmacological characterization of alpha and beta receptors mediating vasomotor re- sponse of cerebral arteries in vitro. Circ: Res. 35, 835-849.

FLAMM, E. S., KIN, J., LIN, J. (1975). Phosphodiesterase inhibitors and cerebral vasospasm. Arch. Nurol: 32, 569-71.

FISHER, C. M. Personal Communication.

GOODMAN, L. F. and GILMAN, A. (1970). The Pharmacological basis of therapeutics. The MacMillan Co. Fourth Edition.

KAPP, J., MAHALEY, M. S., ODOM, G. L. (1968). Cerebral arterial spasm. Journal of Neurosurgery: 29, 331-356.

KATZ, A. N. (1975). Congestive heart failure. Role of altered myocardial cellular control. New England Journal of Medicine: 293, 1184-1191.

LANGFITT, W. (1974). Cerebral circulation and metabolism. Summary of International Symposium June 6-10, 1973. Journal of Neurosurgery: 40, 561-576.

LATORRE, E., PATRONO, C., FORTUNA, A. and GROSSI-BELLONI, D. (1974). Role of prostaglandin $F_{2}$ in human central vasospasm. Journal of Neurosurgery: 41, 293-299.

LOWE, 1. F., and GILBOE, D. D. (1971). Demonstration of alpha and beta adrenergic receptors in canine cerebral vasculature. Stroke: 2, 193-200.

PELOFSKY, S., JACOBSON, E. D. and FISHER, R. G. (1972). Effects of PGEı on experimental cerebral vasospasm. Journal of Neurosurgery: 36, 634.

PEERLESS, S., YASARGIL, M. (1971). Adrenergic innervation of the cerebral blood vessels in the rabbit. Journal of Neurosurgery: $35,148-154$.

PETERSON, E. W., METUZALS, J., JOHNSON, D. H. (1969). The relief of cerebral vasospasm by topically applied ethylene diamine tetra acetic acid (EDTA) Excerpta Medica. International Congress Series: 192, 72.

PETERSON, E. W., SEARLE, R., MANDY, F. F., LEBLANC, R. and BOSC. M. (WADDELL, W. G.) (1973a). A chronic experimental model for the production of subarachnoid hemorrhage. British Journal of Surgery.

PETERSON, E. W., MANDY, F. F., SEARLE, R. and LEBLANC, R. (1973b).
Reversal of cerebral vasospasm. Lancet: 1 , 1513.

PETERSON, E. W., SEARLE, R., MANDY, F., LEBLANC, R. and BOSC, $M .(1973 c)$. Investigation of cerebral vasospasm and its reversal using dibutyryl cyclic AMP and theophylline. J. Excerpta Medica International Congress Series No. 293, the $\mathrm{V}$ International Congress of Neurological Surgery, Tokyo, Japan, October.

PETERSON, E. W., SEARLE, R., MANDY, F. F. and LEBLANC, R. (1973d). The reversal of experimental vasospasm by 3 ' 5 '-adenosine monophosphate. Journal of Neurosurgery: December, 39, 6.

PETERSON, E. W., LEBLANC, R., SEARLE, R. and MANDY, F. (1975a). Some considerations on cerebral vasospasm. Am. Heart J: 89, 124-126.

PETERSON, E. W., LEBLANC, R., LEBEL, F. (1975b). Cyclic adenosine Monophosphate antagonism of prostaglandin induced vasospasm. Surg. Neurol.: 4, 490-496.

POOL, J. L. (1958). Cerebral vasospasm. New England Journal of Medicine. 254, 1259-1264.

ROBISON, A. G., BUTCHER, R. W., SUTHERLAND, E. W. (1971a). Cyclic AMP, New York, Academic Press.

ROBISON, A. G., BUTCHER, R. W., SUTHERLAND, E. W. (1971b). Adenylcyclase as an adrenergic receptor. Ann. N.Y. Acad. Sci.: 185, 703-723.

SOMLYO, A. P., SOMLYO, A. V. (1970). Vascular smooth muscle: II Pharmacology and normal and hypertensive vessels. Pharmacol. Rev. 22, 353.

TRINER, L., VULLIEMOZ, L., SCHWARTZ, I., NAHAS G. G. (1970). Cyclic phosphodiestrase activity and the action of papaverine. Biochem. Biophys. Res. Commun.: 40, 64-69.

WHITE, R. P., HAGEN, A. A. MORGAN, H., et al (1975). Experimental study on the genesis of cerebral vasospasm. Stroke: 6 , 52-57.

WOLFE, L. S., MAMER, O. A. (1975). Measurement of prostaglandin $F_{2}$ levels in human cerebrospinal fluid in normal and pathological conditions. Prostaglandins: 9 , 183-192. 